\title{
Iron Mountain Electromagnetic Results
}

Gail Heath

July 2012

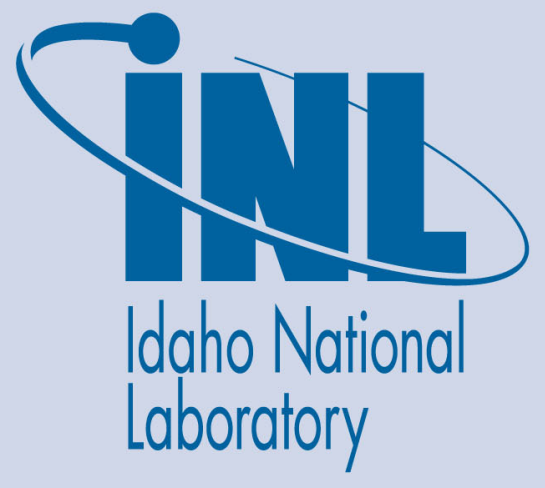

The INL is a U.S. Department of Energy National Laboratory operated by Battelle Energy Alliance 
INL/EXT-12-26791

\title{
Iron Mountain Electromagnetic Results
}

\author{
Gail Heath
}

July 2012

\section{Idaho National Laboratory \\ Idaho Falls, Idaho 83415}

http://www.inl.gov

\author{
Prepared for the \\ Environmental Protection Agency \\ and for the \\ U.S. Department of Energy \\ Under DOE Idaho Operations Office \\ Contract DE-AC07-05ID14517
}




\section{Iron Mountain}

\section{Electromagnetic Results}

Gail Heath

$7 / 31 / 2012$

The project goal was to evaluate several geophysical methods to determine competence of the concrete plugs and orientation of the stopes. 


\section{Contents}

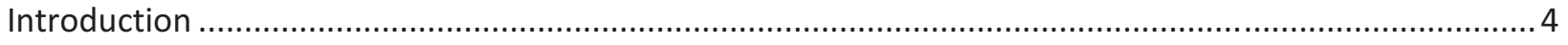

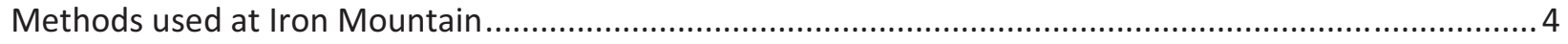

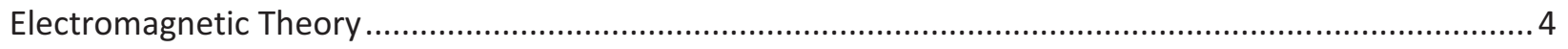

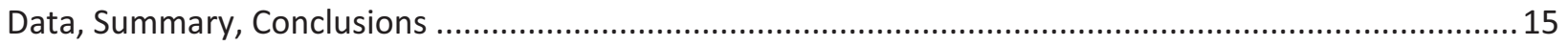

Figure 1: The basic principle of operation of the FDEM method is illustrated (from NGA) ....................... 5

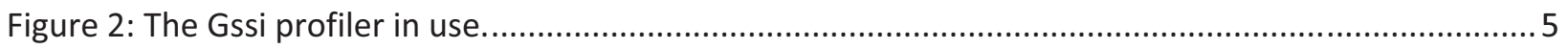

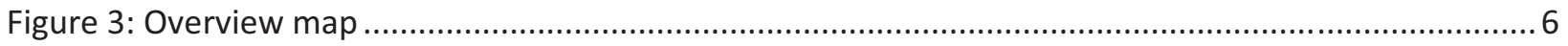

Figure 4: Overview with survey locations of key features ..................................................................

Figure 5: Conductivity $2000 \mathrm{~Hz} 90$ degrees. $\mathrm{A}$ is a very conductive geological unit, $\mathrm{B}$ is the transition from one geological unit to another, $\mathrm{C}$ is a very resistive anomaly, $\mathrm{D}$ is a conductive area this is at the $2 \mathrm{E}$ and $5 \mathrm{E}$ plugs this is most likely that the plugs are moist or have wet muck behind them, at location $\mathrm{E}$ there is an anomaly most likely produced by the bypass, Location $\mathrm{F}$ is a resistive area that is most likely dry or more competent rock location $\mathrm{G}$ show an anomaly at $6 \mathrm{E}$ so again this is either a seeping plug or wet muck behind a thinning structure, $\mathrm{H}$ has a large signature that is from 7E and indicates that this plug has a larger seep and should be examined, I is an area with little structure present in the data here.

Figure 6: Conductivity $6000 \mathrm{~Hz} 90$ degrees. A is a very conductive geological unit, B is the transition from one geological unit to another, $\mathrm{C}$ is a very resistive anomaly, $\mathrm{D}$ is a little more conductive this is at the $2 \mathrm{E}$ and $5 \mathrm{E}$ plugs this is most likely that the plugs are moist or have wet muck behind them, at $\mathrm{E}$ there are two small anomalies most likely produced by the bypass, location $\mathrm{F}$ show an anomaly at $6 \mathrm{E}$ so again this is either and seeping plug or wet muck behind a thinning structure, $G$ has a large signature that is from $7 \mathrm{E}$ and indicates that this plug has a larger seep and should be examined, $\mathrm{H}$ is an area with little structure present in the data here.

Figure 7: Inphase $2,000 \mathrm{~Hz}$ at 90 degrees. $A$ is a very conductive geological unit, $B$ is the transition from one geological unit to another, $\mathrm{C}$ is a small , $\mathrm{D}$ is a larger anomaly a little farther down the adit at $2 \mathrm{E}$ and $5 \mathrm{E}$ plugs is an area that is most likely where the plugs are moist or have wet muck behind them, at $\mathrm{E}$ there is an anomaly most likely produced by the bypass as well as some influence from plug $3 \mathrm{E}$ this plug seems to be in better shape than the other plugs here, location $\mathrm{F}$ has a signature that is from $6 \mathrm{E}$ and indicates that this plug has a larger seep or one nearby and should be examined, $\mathrm{H}$ is an area that has a high amplitude in the data and is associated with $7 \mathrm{E}$ this plug needs to be examined, I is an area with a structure present in the data here. 
Figure 8: Inphase $6,000 \mathrm{~Hz}$ at 90 degrees. $A$ is a very conductive geological unit, $B$ is the transition from one geological unit to another, $C$ is a small as are the anomalies at $D, E, F, G$, and $H$ is an area that has a high amplitude in the data and is associated with $7 \mathrm{E}$ this plug needs to be examined, I is an area with a structure present in the data here.

Figure 9: Inphase $10,000 \mathrm{~Hz}$ at 90 degrees. $A$ is a very conductive geological unit, $B$ is the transition from one geological unit to another, $\mathrm{C}$ is a small as are the anomalies at $\mathrm{D}, \mathrm{E}, \mathrm{F}$, and $\mathrm{F}$ is an area that has a high amplitude in the data and is associated with 7E this plug needs to be examined, $G$ is an area with a structure present in the data here.

Figure 10: Quadrature $2,000 \mathrm{~Hz}$ at 90 degrees. $A$ is a response from a geological unit, $B$ is the transition from one geological unit to another, $C$ is a small , $D$ is a larger resistive anomaly, a little farther down the adit at $2 \mathrm{E}$ and $5 \mathrm{E}$ plugs is an area that is most likely where the plugs are moist or have wet muck behind them, at $E$ there is an anomaly most likely produced by the bypass as well as some influence from plug $3 \mathrm{E}$ this plug seems to be in better shape than the other plugs here, location $\mathrm{F}$ has a signature that is from $4 \mathrm{E}$ and indicates that this plug has is most likely dryer or less conductive material, $\mathrm{G}$ is near plug $6 \mathrm{E}$ and shows an area that is more conductive, wet and or geologic structure, $\mathrm{H}$ is an area that has a high amplitude in the data and is associated with $7 \mathrm{E}$ this plug needs to be examined, I is an area with a structure present in the data here.

Figure 11: Quadrature $2,000 \mathrm{~Hz}$ at 90 degrees. $\mathrm{A}$ is a response from a geological unit, $\mathrm{B}$ is the transition from one geological unit to another, $C$ is a small , D is a larger resistive anomaly, a little farther down the adit at $2 \mathrm{E}$ and $5 \mathrm{E}$ plugs is an area that is most likely where the plugs are moist or have wet muck behind them, at $E$ there is an anomaly most likely produced by the bypass as well as some influence from plug $3 \mathrm{E}$ this plug seems to be in better shape than the other plugs here, location $\mathrm{F}$ has a signature that is from $4 \mathrm{E}$ and indicates that this plug has is most likely dryer or less conductive material, $\mathrm{G}$ is near plug $6 \mathrm{E}$ and shows an area that is more conductive, wet and or geologic structure, $\mathrm{H}$ is an area that has a large response in the data and is associated with 7E, this plug needs to be examined, I is an area with a structure present in the data here. 


\section{Introduction}

Iron Mountain Mine is located seventeen miles northwest of Redding, CA. After the completion of mining in early 1960s, the mine workings have been exposed to environmental elements which have resulted in degradation in water quality in the surrounding water sheds. In 1985, the EPA plugged ore stoops in many of the accessible mine drifts in an attempt to restrict water flow through the mine workings. During this process little data was gathered on the orientation of the stopes and construction of the plugs. During the last 25 years, plugs have begun to deteriorate and allow acidic waters from the upper workings to flow out of the mine. A team from Idaho National Laboratory (INL) performed geophysical surveys on a single mine drift and 3 concrete plugs. The project goal was to evaluate several geophysical methods to determine competence of the concrete plugs and orientation of the stopes.

\section{Methods used at Iron Mountain}

In order to conduct a proper analysis of the three concrete plugs and the mine drift, 3 different geophysical methods were conducted, Ground penetrating radar $(500 \mathrm{MHz}$ and $1.6 \mathrm{GHz})$, sound propagation (Ultra Sonics), and frequency domain electromagnetic induction (EM Profiler EMP-400). The Ultra Sonics method did not yield any useful information due to the depth of penetration achieved. The GPR data is presented in an additional appendix to the main report. This report appendix presents the results of the third method, frequency domain electromagnetic induction.

\section{Electromagnetic Theory}

Frequency domain electromagnetic is a method that uses the inductive properties of a continuous primary electromagnetic field to measure the conductivity of the material through which the field passes. The conductivity of the geology is influenced by soil grain size, mineralogy and can both identify lateral boundaries between different materials and lithology. As a result, frequency domain methods can be used for many applications such as the delineation of shallow high-TDS and contaminant plumes and the delineation of weathered, altered, or vertical water-bearing zones in bedrock. Electromagnetic methods can be used to distinguish the boundaries between contrasting materials with a very high degree of resolution. Frequency domain methods are particularly useful where there is a large area to investigate, as an extremely large number of measurements can be made quickly and cost effectively. 
The basic principle of operation of the FDEM method is illustrated in figure 2. A transmitter coil radiates a frequency fixed electromagnetic field which induces electrical currents (termed eddy currents, Je) in the earth below the coil. These eddy currents in turn generate a secondary magnetic field (Bs). The receiver coil detects and measures this secondary field. The instrument output, calibrated to read in units of terrain conductivity (apparent conductivity), is obtained by comparing the strength of the quadrature phase component of the secondary field to the strength of the primary field. The apparent conductivity measurement represents a weighted average of subsurface conductivity from the ground surface to the effective depth of

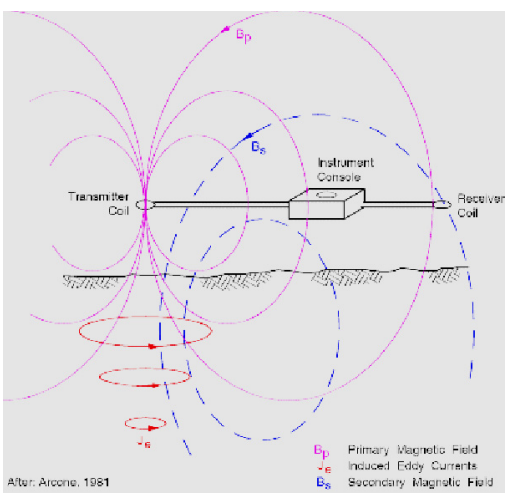

Figure 1: The basic principle of operation of the FDEM method is illustrated (from NGA) exploration of the instrument. Since electrical conductivity of soil correlates strongly with soil propertie5s, FDEM is a powerful tool for mapping soils and changes in soil types.( from NGA)

Electromagnetic induction instruments find application in many different types of geological and environmental areas. EM surveys have also been used extensively for the detection of conductive geologic media such as geologic structures, clays and ferrous mineral deposits.

The Profiler EMP-400 is a frequency domain, electromagnetic profiling system. The Profiler EMP-400 is a multi-frequency electromagnetic induction sensor where data can be collected in both the vertical (VDM) and horizontal (HDM) dipole modes. By acquiring multiple frequencies, the user can select the frequencies that provide the best results for a specific application.

The GSSI profiler was used to define the stope orientation in the drift. The profiler was fixed to a PVC pole, held up to the roof of

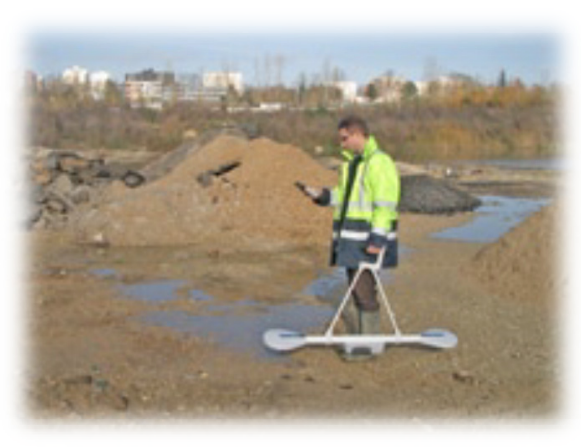

Figure 2: The Gssi profiler in use. the drift and then walked from the beginning of the drift at the five-spot to a point at the end of the drift survey. Once the center of the ceiling had been surveyed, the profiler was moved to a 45 degree angle from the roof center line, then to 90 degrees, 135 degrees, and finally a survey near the floor. One final survey was completed by holding the profiler waist high, in a vertical dipole mode walking down the center of the drift. The information from this survey is presented in the data section of this report. 


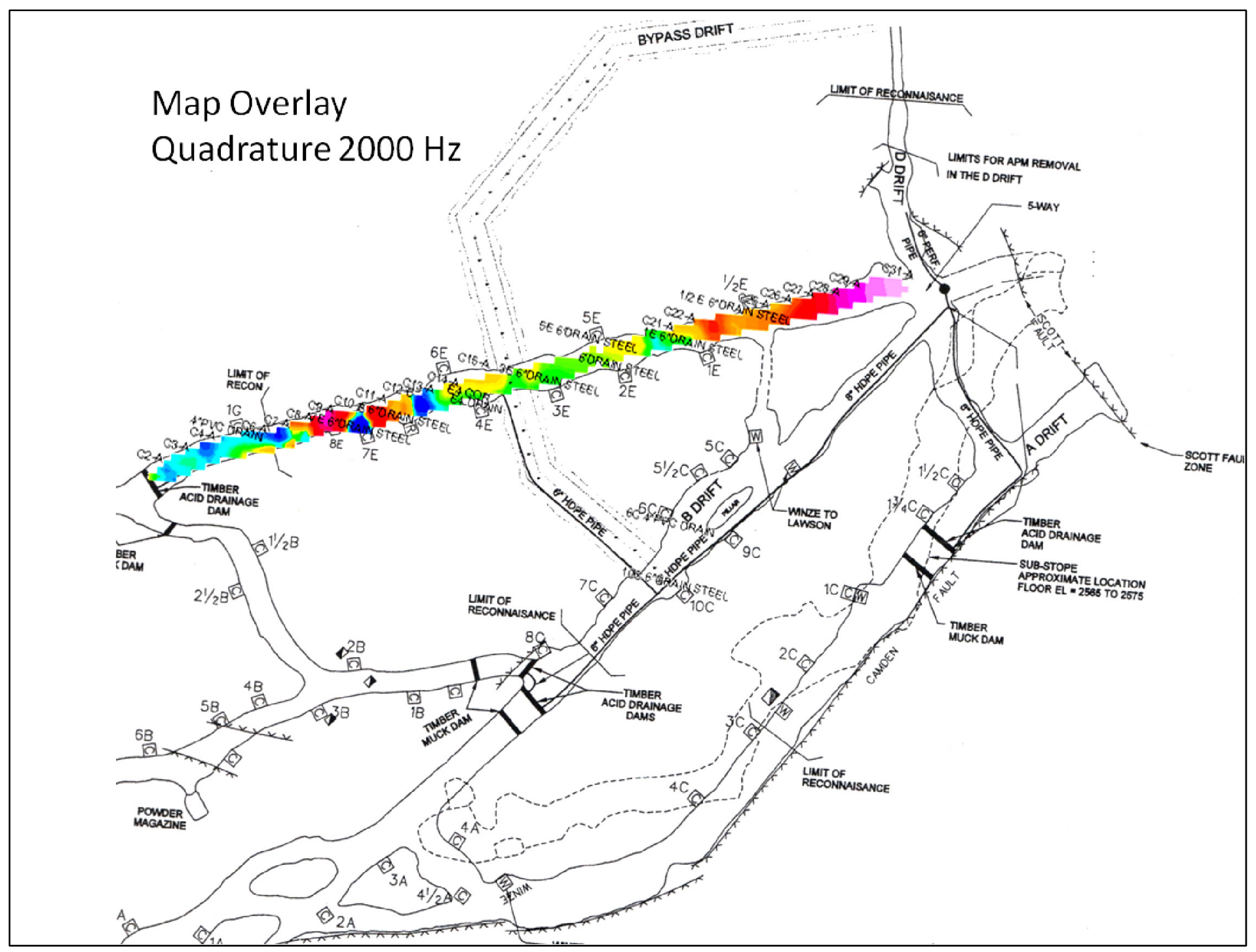

Figure 3: Overview map 


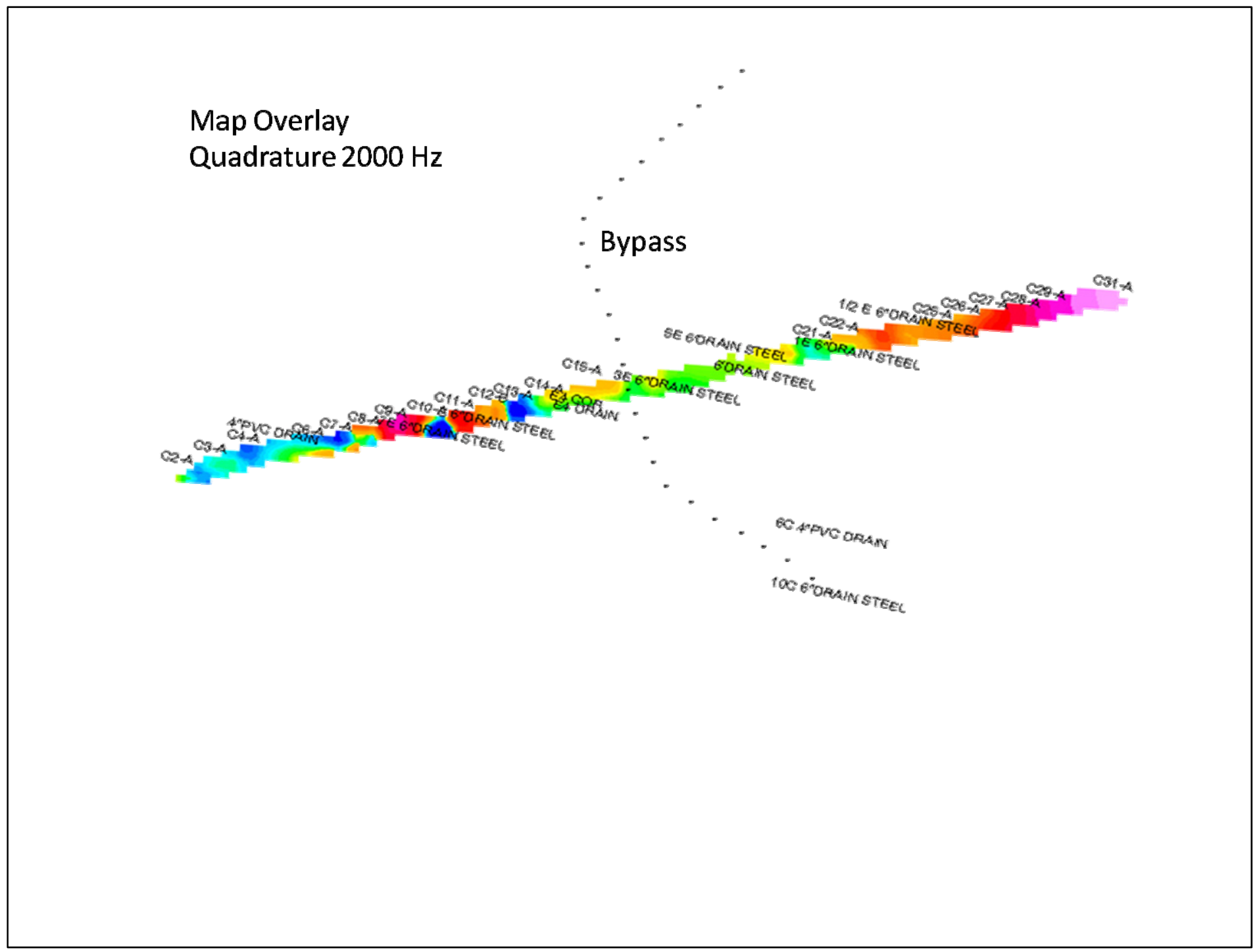

Figure 4: Overview with survey locations of key features 


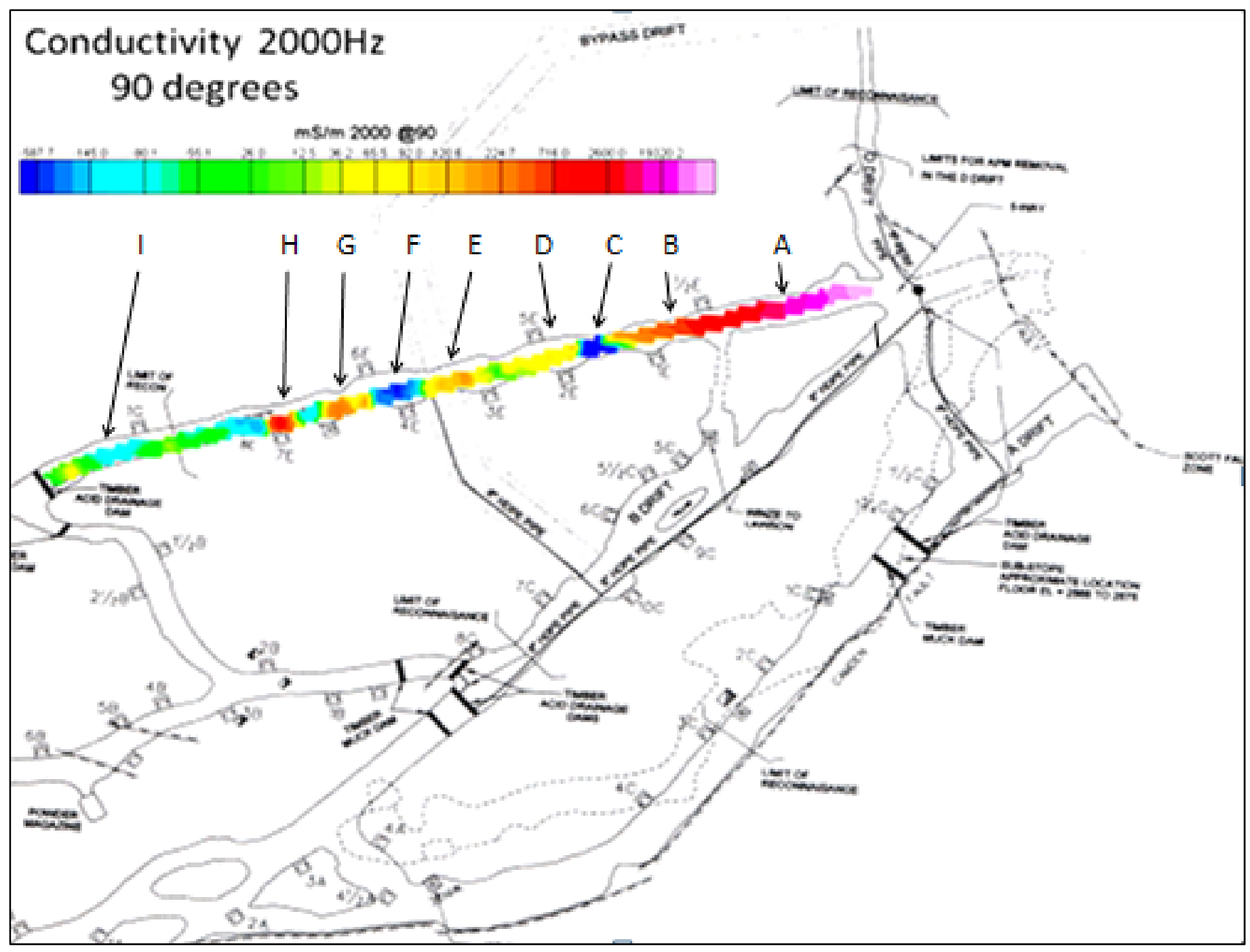

Figure 5: Conductivity $2000 \mathrm{~Hz} 90$ degrees. A is a very conductive geological unit, B is the transition from one geological unit to another, $\mathrm{C}$ is a very resistive anomaly, $\mathrm{D}$ is a conductive area this is at the $2 \mathrm{E}$ and $5 \mathrm{E}$ plugs this is most likely that the plugs are moist or have wet muck behind them, at location $\mathrm{E}$ there is an anomaly most likely produced by the bypass, Location $\mathrm{F}$ is a resistive area that is most likely dry or more competent rock location $\mathrm{G}$ show an anomaly at $6 \mathrm{E}$ so again this is either a seeping plug or wet muck behind a thinning structure, $\mathrm{H}$ has a large signature that is from $7 \mathrm{E}$ and indicates that this plug has a larger seep and should be examined, I is an area with little structure present in the data here. 


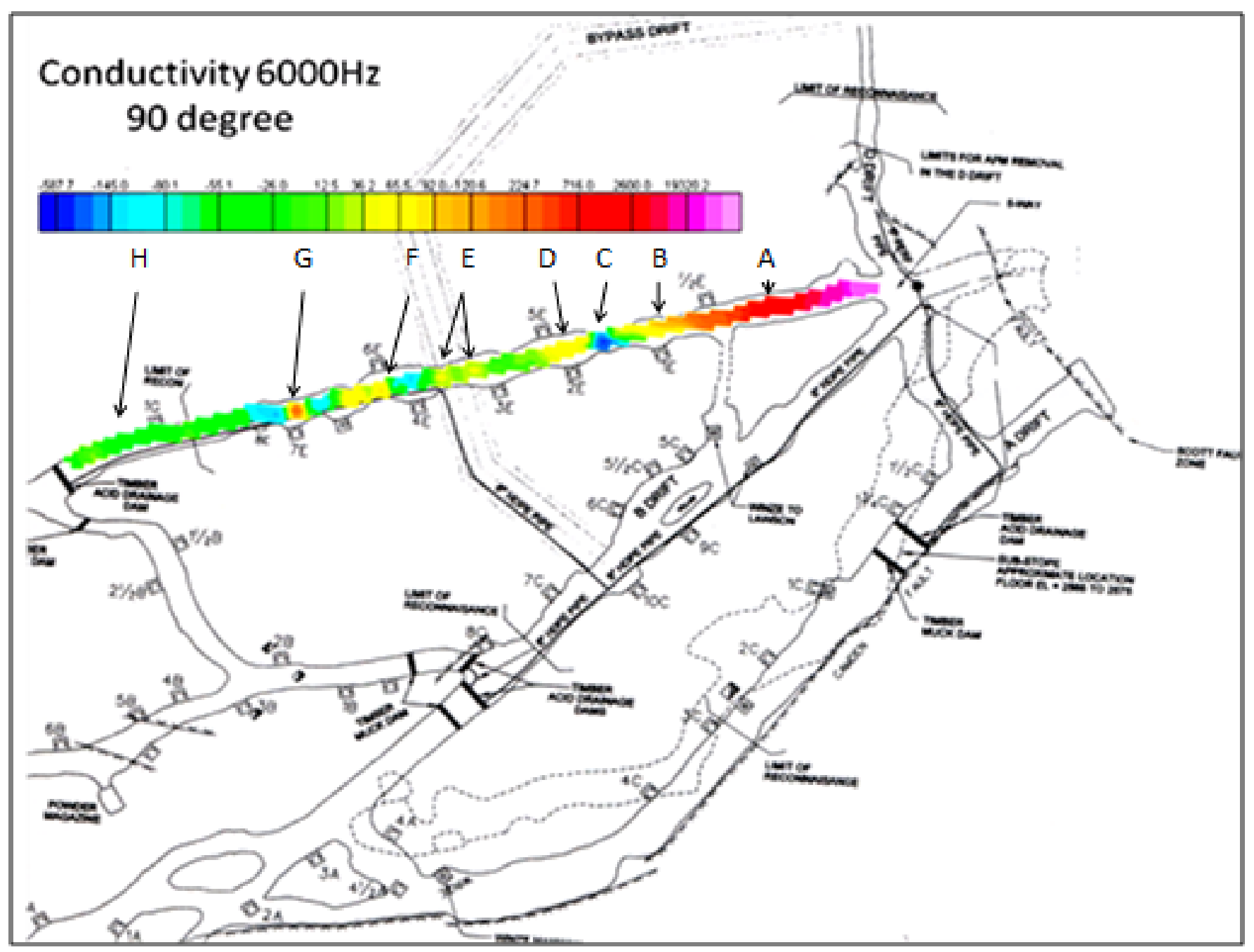

Figure 6: Conductivity $6000 \mathrm{~Hz} 90$ degrees. A is a very conductive geological unit, B is the transition from one geological unit to another, $\mathrm{C}$ is a very resistive anomaly, $\mathrm{D}$ is a little more conductive this is at the $2 \mathrm{E}$ and $5 \mathrm{E}$ plugs this is most likely that the plugs are moist or have wet muck behind them, at $\mathrm{E}$ there are two small anomalies most likely produced by the bypass, location $\mathrm{F}$ show an anomaly at $6 \mathrm{E}$ so again this is either and seeping plug or wet muck behind a thinning structure, $\mathrm{G}$ has a large signature that is from 7E and indicates that this plug has a larger seep and should be examined, $\mathrm{H}$ is an area with little structure present in the data here. 


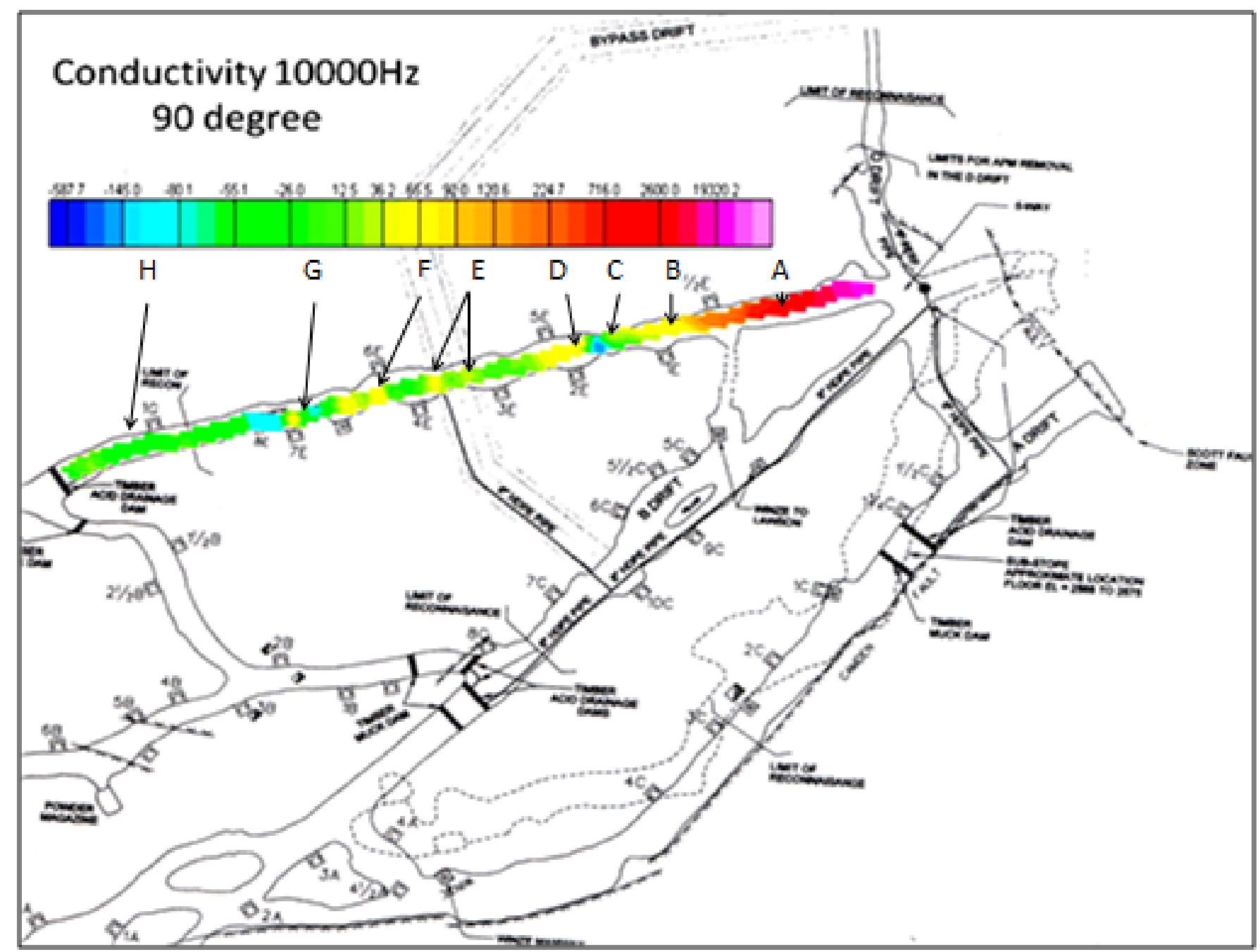

Figure 7: Conductivity $10,000 \mathrm{~Hz}$ at 90 degrees. A is a very conductive geological unit, $\mathrm{B}$ is the transition from one geological unit to another, $\mathrm{C}$ is a very resistive anomaly, $\mathrm{D}$ is a slightly conductive area that is at the $2 \mathrm{E}$ and $5 \mathrm{E}$ plugs this is most likely that the plugs are moist or have wet muck behind them, at $E$ there is an anomaly most likely produced by the bypass as well as some influence from plug $3 \mathrm{E}$ this plug seems to be in better shape than the other plugs here, $\mathrm{F}$ has a signature that is from $6 \mathrm{E}$ and indicates that this plug has a larger seep or one nearby and should be examined, $G$ is an area that is very conductive and is associated with $7 \mathrm{E}$ this plug needs to be examined, $\mathrm{H}$ is an area with little structure present in the data here. 


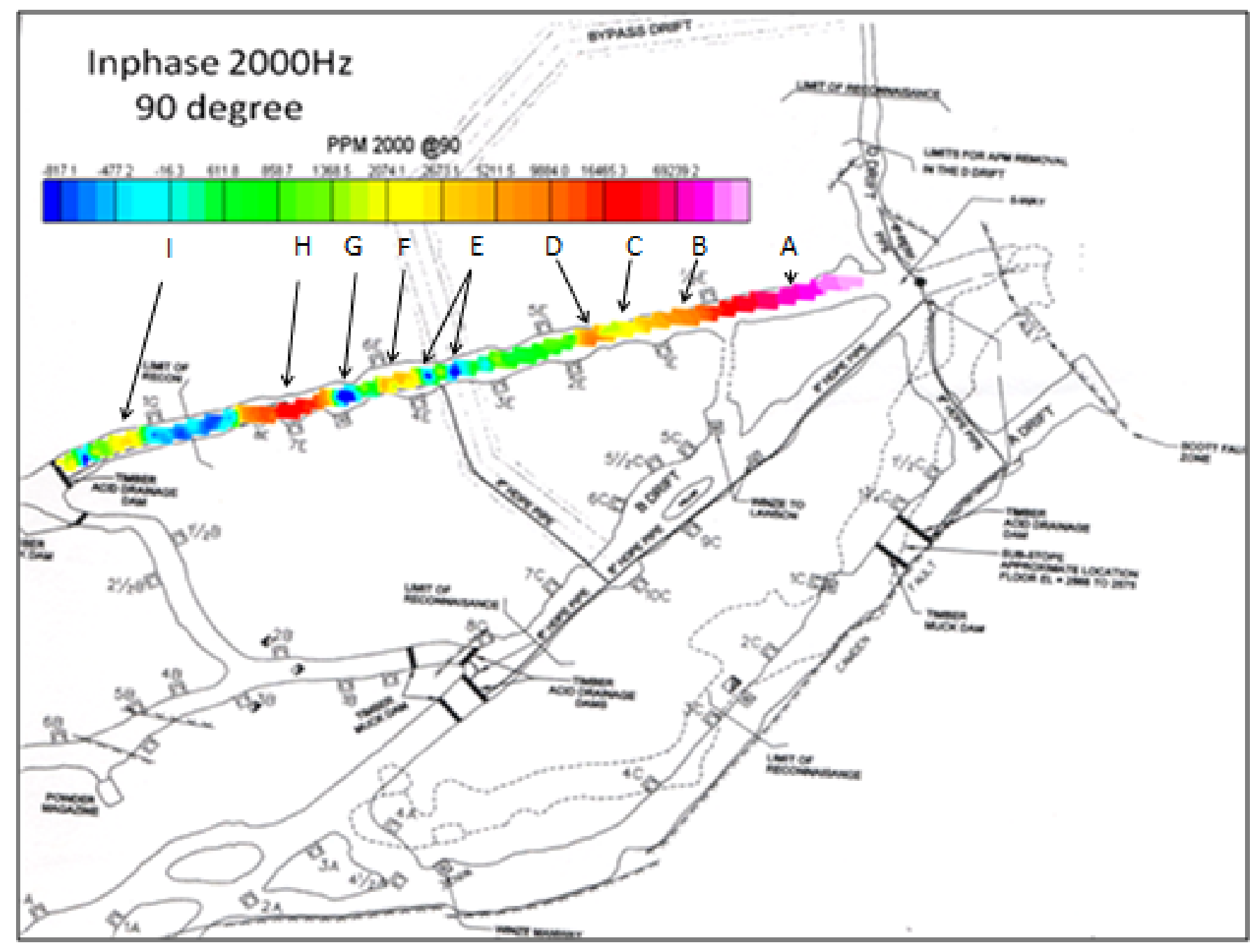

Figure 7: Inphase $2,000 \mathrm{~Hz}$ at 90 degrees. A is a very conductive geological unit, B is the transition from one geological unit to another, $\mathrm{C}$ is a small , D is a larger anomaly a little farther down the adit at $2 \mathrm{E}$ and $5 \mathrm{E}$ plugs is an area that is most likely where the plugs are moist or have wet muck behind them, at $E$ there is an anomaly most likely produced by the bypass as well as some influence from plug $3 \mathrm{E}$ this plug seems to be in better shape than the other plugs here, location $\mathrm{F}$ has a signature that is from $6 \mathrm{E}$ and indicates that this plug has a larger seep or one nearby and should be examined, $\mathrm{H}$ is an area that has a high amplitude in the data and is associated with 7E this plug needs to be examined, I is an area with a structure present in the data here. 


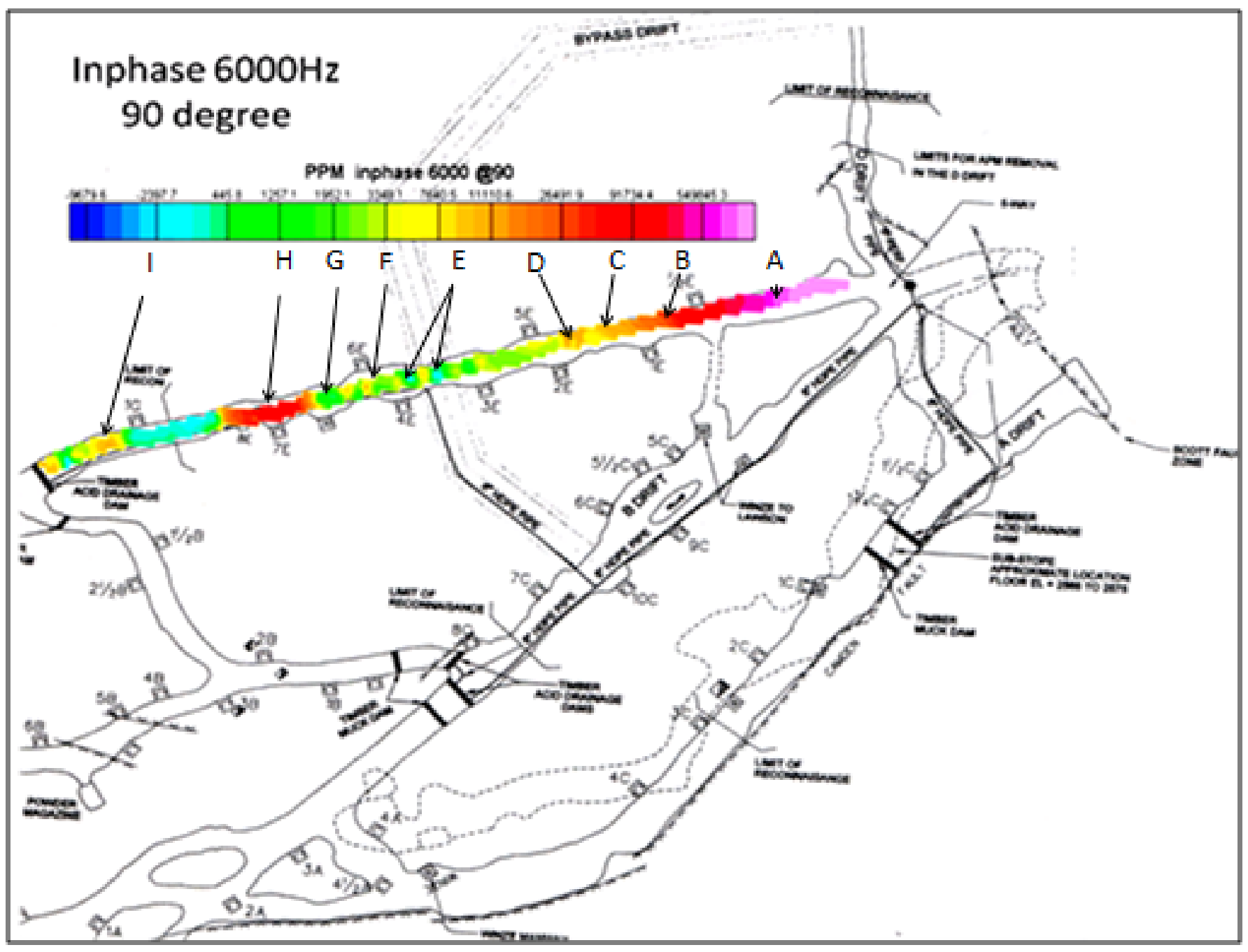

Figure 8: Inphase $6,000 \mathrm{~Hz}$ at 90 degrees. $A$ is a very conductive geological unit, $\mathrm{B}$ is the transition from one geological unit to another, $\mathrm{C}$ is a small as are the anomalies at $\mathrm{D}, \mathrm{E}, \mathrm{F}, \mathrm{G}$, and $\mathrm{H}$ is an area that has a high amplitude in the data and is associated with $7 \mathrm{E}$ this plug needs to be examined, I is an area with a structure present in the data here. 


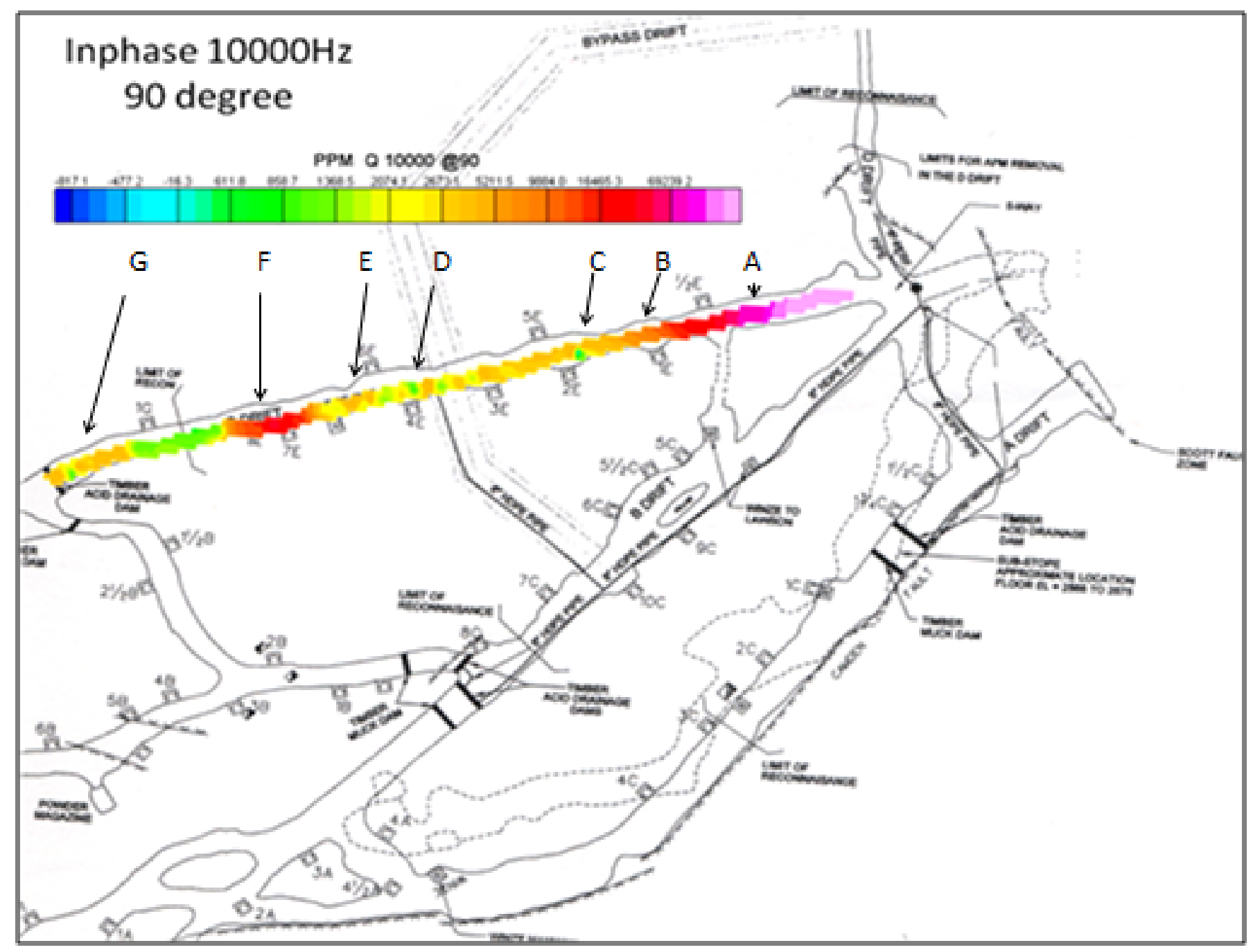

Figure 9: Inphase $10,000 \mathrm{~Hz}$ at 90 degrees. $A$ is a very conductive geological unit, $B$ is the transition from one geological unit to another, $\mathrm{C}$ is a small as are the anomalies at D, E, F, and F is an area that has a high amplitude in the data and is associated with $7 \mathrm{E}$ this plug needs to be examined, $\mathrm{G}$ is an area with a structure present in the data here. 


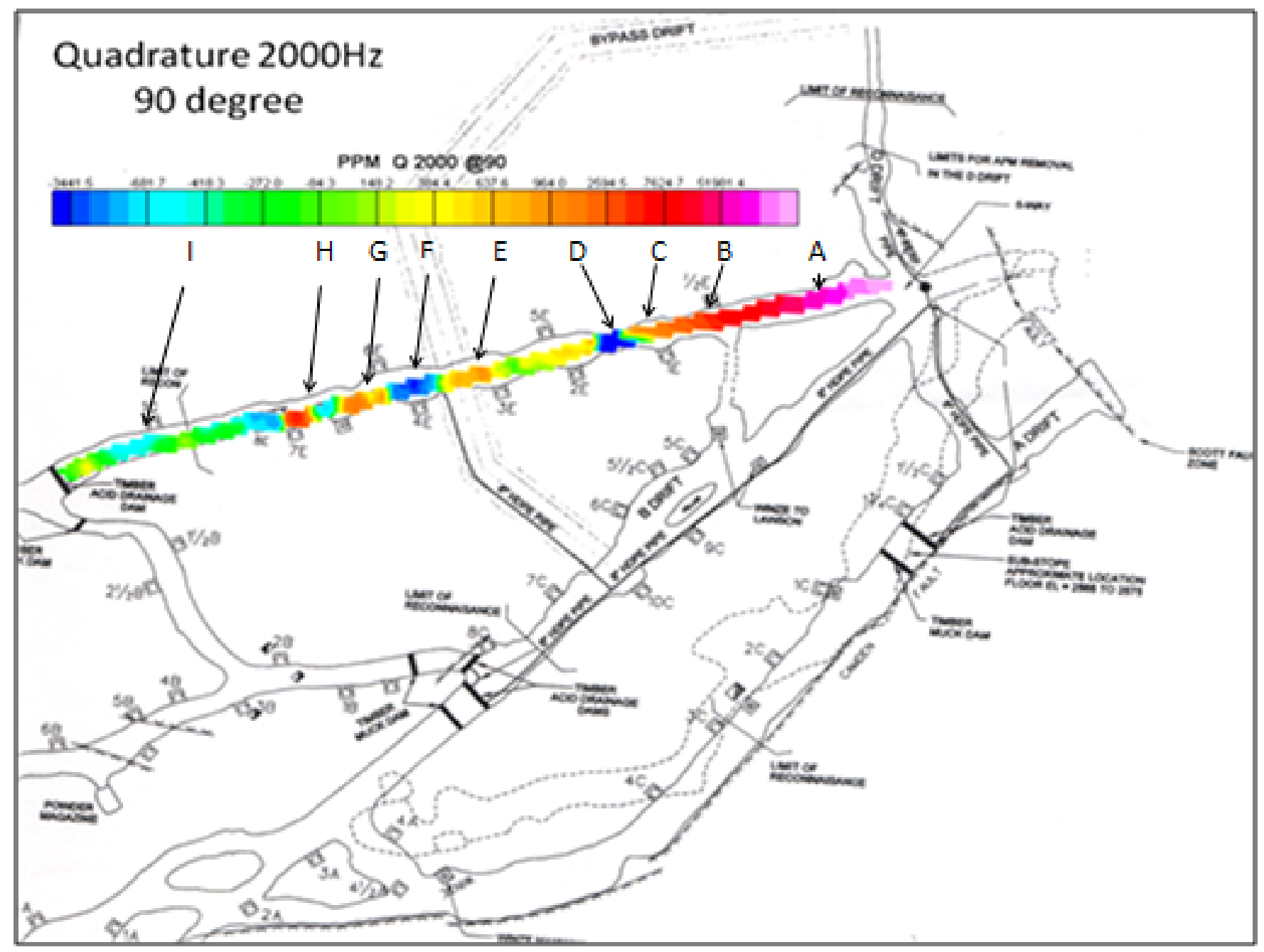

Figure 10: Quadrature $2,000 \mathrm{~Hz}$ at 90 degrees. $A$ is a response from a geological unit, $\mathrm{B}$ is the transition from one geological unit to another, $C$ is a small , D is a larger resistive anomaly, a little farther down the adit at 2E and 5E plugs is an area that is most likely where the plugs are moist or have wet muck behind them, at $E$ there is an anomaly most likely produced by the bypass as well as some influence from plug $3 \mathrm{E}$ this plug seems to be in better shape than the other plugs here, location $\mathrm{F}$ has a signature that is from $4 \mathrm{E}$ and indicates that this plug has is most likely dryer or less conductive material, $\mathrm{G}$ is near plug $6 \mathrm{E}$ and shows an area that is more conductive, wet and or geologic structure, $\mathrm{H}$ is an area that has a high amplitude in the data and is associated with $7 \mathrm{E}$ this plug needs to be examined, I is an area with a structure present in the data here. 


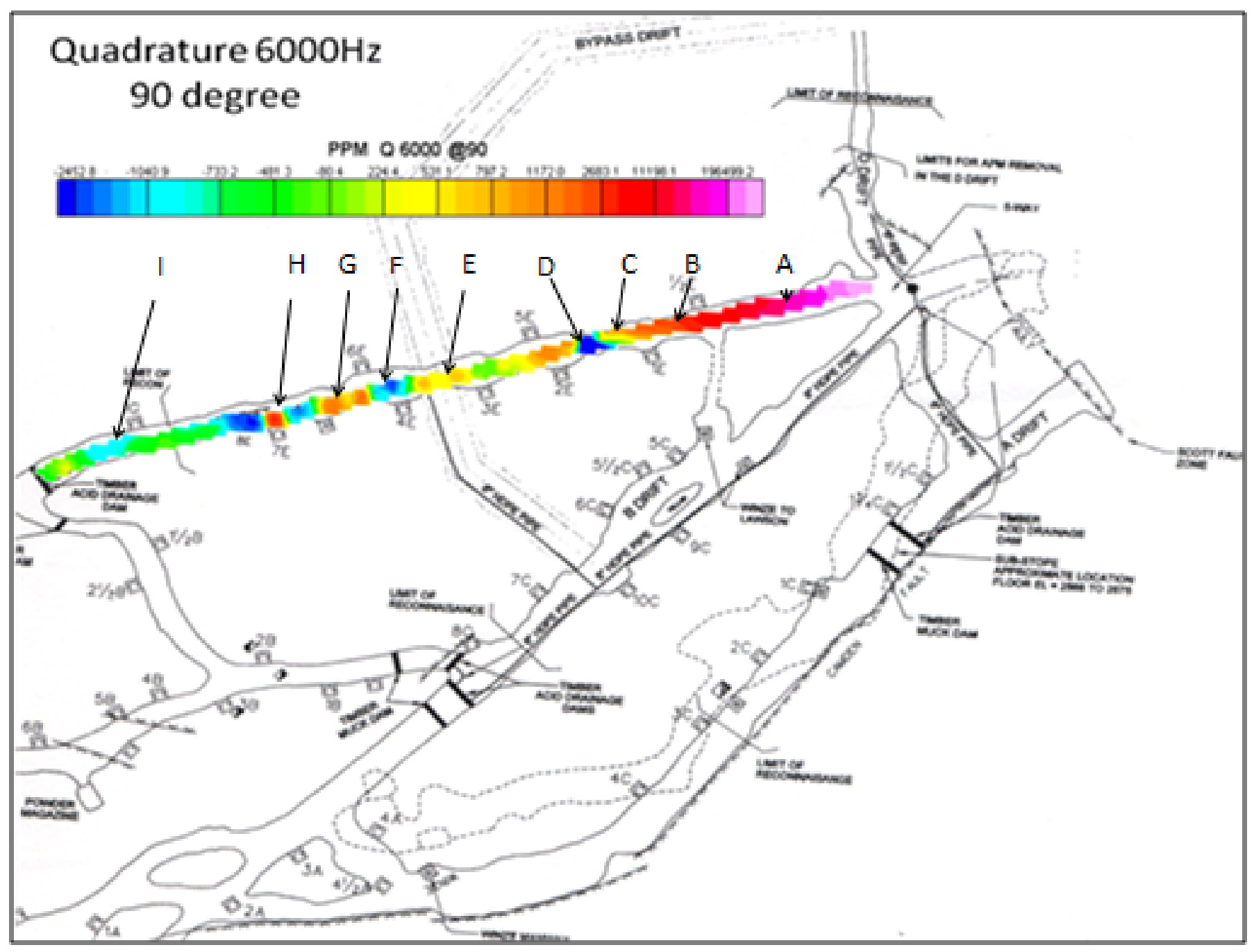

Figure 11: Quadrature $2,000 \mathrm{~Hz}$ at 90 degrees. $A$ is a response from a geological unit, $B$ is the transition from one geological unit to another, $C$ is a small , D is a larger resistive anomaly, a little farther down the adit at 2E and 5E plugs is an area that is most likely where the plugs are moist or have wet muck behind them, at $E$ there is an anomaly most likely produced by the bypass as well as some influence from plug $3 \mathrm{E}$ this plug seems to be in better shape than the other plugs here, location $\mathrm{F}$ has a signature that is from $4 \mathrm{E}$ and indicates that this plug has is most likely dryer or less conductive material, $\mathrm{G}$ is near plug $6 \mathrm{E}$ and shows an area that is more conductive, wet and or geologic structure, $\mathrm{H}$ is an area that has a large response in the data and is associated with $7 \mathrm{E}$, this plug needs to be examined, I is an area with a structure present in the data here.

\section{Data, Summary, Conclusions}

1. The profiler data was processed using Geosoft software and then the results were superimposed over existing mine maps. Correlations within the data and with the existing mapped structures were determined. The maps (Figure 3 to 11) are processed data from the GSSI profiler and show the Inphase (amplitude), the Quadrature (phase information), and a 
calculated apparent conductivity at different frequencies. For clarity the results are discussed on each of the following figures with a brief overview of results and recommendations here. The data show a change in geology from locations $A$ though $B$ (see figure 3 ). Location $\mathrm{C}$ has a large resistive response that could be a geologic feature or an

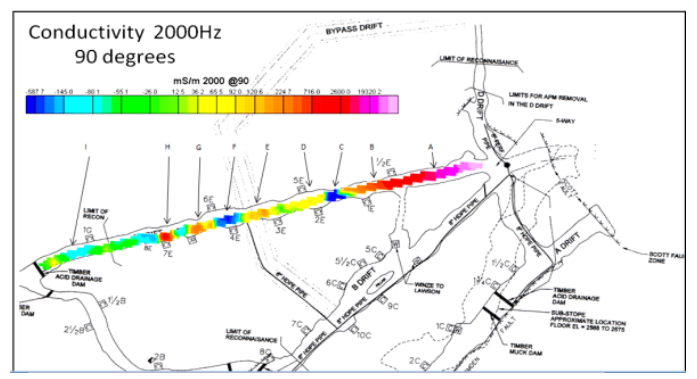

Figure 12: Overview of anomalies area that is dry and or competent. Locations $D$ and $\mathrm{E}$ show more conductive areas at plugs $5 \mathrm{E}$ and $2 \mathrm{E}$ and as a result, it is recommended to inspect them. Location $\mathrm{F}$ has a response similar to that of location $\mathrm{C}$. Plug $6 \mathrm{E}$ at location $\mathrm{G}$ is more conductive and is an area that is recommended for site inspection. Location $\mathrm{H}$ is plug 7E and is recommended for closer site inspection as all data sets indicate that this small area is more conductive than anything on that end of the adit. The areal extent of this response suggests that this is not a geologic contact as in location A, but a problem with the performance of plug $7 \mathrm{E}$. Location I is most likely a geological structure that is seen.

1. Plug $1 / 2 \mathrm{E}$

2. Plug $1 \mathrm{E}$

3. Plug $2 \mathrm{E}$

4. Plug $3 E$

5. Plug 4E

6. Plug 5E

7. Plug $6 \mathrm{E}$

8. Plug 7E
No obvious issues in the data

This is a moderatly conductive area, inspection recomended

No obvious issues in the data

No obvious issues in the data

No obvious issues in the data

This is a moderatly conductive area, inspection recomended

Recommended for close inspection

Recommended for close inspection 